\title{
The Countermeasures Research on Curriculum Ideological and Political Education in the English Course Teaching
}

\author{
Yuan Wang ${ }^{1, *}$ \\ ${ }^{1}$ School of Foreign Language, Kunming University, Kunming, Yunnan,650000, China \\ *Corresponding author. Email: Willa2118009@163.com
}

\begin{abstract}
This paper probes into the countermeasures research of curriculum ideological and political education in the English course teaching for no-English major students. Here our teaching group analyzed the questionnaire completed by 200 students and listened to English classes at random and then summarized the necessity and feasibility of the combination of English course and ideological and political education. In addition, this paper puts forward four principles, exact teaching design and reforming in teaching methods and teaching materials as well during the implementation of curriculum ideological and political education through English courses. To a certain extent, the research can serve as functional guidance in the administration of ideological and political education in humanities courses, which is not confined to English course.

Keywords: ideological and political education, countermeasures, curriculum
\end{abstract}

\section{INTRODUCTION}

\subsection{The Background}

With the highly developing economics and culture, China is being pushed into a new era developing at a high speed in an international environment of great diversity of values and views. Faced with the changing international atmosphere, college students are supposed to form their correct values and ways of thinking to make wise judgment and decisions. Therefore, China's central government has put forward the requirements of all-round education in the national education and personnel training as well in order to improve and enhance the ideological and political work in educational system widely and profoundly. Accordingly, the prime goal of advanced education is not only to transmit professional knowledge but also to cultivate individuals comprehensively thus to build up sound personality and shape correct three views and values. For the sake of all-round education, the ideological and political education of curriculum accordingly plays a critical role in the process of the high education. In the practical teaching and training of high education, we should attach great importance to the integration of professional knowledge and ideological and political ideas. Chinese government has issued a set of policies together with related documents to ensure and cement ideological and political work in colleges and universities. All of these documents and policies require college education to strengthen the ideological and political work in practical teaching and training activities giving full use of classes naturally in administration of ideological and political education. Teaching should penetrate the socialist core values into the professional teaching activities thus enhance the national pride and stimulate patriotic enthusiasm of youth.

\subsection{Review of Related Research}

Although the national education has worked hard for years to launch ideological and political education with special courses named as Marxism, Mao Zedong Though, Three Represents Theory and so on, the effect of such specialized courses is slim. The moral teaching gains less through direct teaching and dictation. Therefore, we should reconsider the teaching design and method to reform for better achievements in this aspect.

"All-round education means all personal of education field should devote into the career of education from diverse perspectives during the whole process of teaching and training"[1], which is the core principle set by the government policies. Curriculum ideological and political education is fresh currently at home while mature relatively abroad. The studies and researches generally fall into the following four categories: 1. The definition of key concepts. The relative viewpoints including "curriculum ideological and political education is a comprehensive teaching method, not an independent course." (AnXiumei,2018); "it is a way of reconstruction of courses bearing the dual tasks of knowledge and ideological education" (li Nan, 2018); "curriculum ideological in major course is critical and effective complement for specialized ideological and political courses, which is the call from the new socialism." (Zhu Rui,2019). These definitions go along with the definition puts forward by Qi Guangwei in 2019, whose points stress the equal roles of 
all kinds of course at college aiming to the same moral education. 2. The necessity and feasibility of the combination of the college education and ideological and political education in English courses. "The prime English course has advantage of ideological and political education." (Chen Wenxia, 2019); "Through ideological and political education in English course, we can cultivate highly qualified bilingual students who are able to behave well in society and workplace." (Shen Yi, 2019); "The college English course is a functional and effective instrument in ideological and political education, which is natural and invisible compared with the specialized ideological and political courses." (Zhu Yi, 2017). Other scholars overseas stress the possibilities and necessities much early. John Dewey holds that moral education should be conducted naturally through diverse courses teaching, which cannot be separated.[2]; Sukhomlonsky also stresses the combination of moral education with intellectual education to form reasonable and rational world view. [3] 3. Studies on the methods and teaching designing researches: "Strengthen the concepts of curriculum ideological and political education in daily teaching and reform the system of courses" (AnXiumei,2018); "weave the ideological and political education into the professional lecturing to update the original teaching materials "( LiPing,2018); “ integrate the socialist core values with the professional lecturing in class taking the characteristics of majors into consideration at the same time to develop professional ethics, to enhance the patriotism, to spread the traditional virtue and Chinese culture" ( Zhu Rui,2019); The infiltration education and its application to moral education is stressed widely abroad. Jim Rogers claims that in his works Freedom to Learn. His humanism ideas about education emphasizes the goal of education is to cultivate well-round individual.[4]; 4. The research on the invisible factors in a particular course. John Dewey puts forward the concept of "Incidental learning" in Democracy and Education: An Introduction to the Philosophy of Education, which holds that students form individual attitudes and feelings during the intellectual learning. [5]; American scholar N . V Awole raises the concept of "hidden curriculum" and derived "hidden moral education" from that.

\subsection{The Innovation}

From the previous researches and studies at home and abroad, we find that the concept of "curriculum of ideological and political education" is relatively fresh whose related researches are hot nowadays. However, the system of class designing for English curriculum ideological and political education is far from intact and integral. This these explores effective and functional strategies and methods to enhance the ideological and political education in English courses in practice to cultivate students with both political integrity and professional competence.

\section{ANALYSIS OF EXISTING CIRCUMSTANCE}

Teachers are the dominating factors in the practice of ideological and political education in daily teaching working, whose attitudes, views, willingness have profound impact on the results and effects of curriculum moral education. In order to get actual feedback, we have listened to 20 teachers' lecturing in class at random. Meanwhile, we distributed 1000 copies of questionnaire to freshmen, sophomores, junior and senior students to get first-hand information about curriculum ideological and political education though English courses. Based on the analysis of teachers' feedback and the results of questionnaires, we summarize the five categories' problems and troubles as follows:

\subsection{Lack of Teaching Objectives.}

The cultivation of well-rounded students is started from practical and reasonable teaching objectives. While the objectives of English courses generally cover the aspects of knowledge, abilities and qualities, the moral education is rarely mentioned. Although some teachers are willing to weave moral education into routine working spontaneously, they are troubled with the fit point and exact material for the combination. Thus, the combination of intellectual education and moral education is rather casual, incoherent and discontinuous. The efficiency of moral education is poor. Top-level designing is critical for thorough and effective curriculum ideological and political education in English teaching.

\subsection{Defects in Teaching Philosophy}

Teaching philosophy is composed of teacher's fundamental views toward teaching, which needs to be updated to satisfy the call of the changing times. For a long time, English learning as second language in China concentrates mainly on the tests and certificates instead of an all-rounded goal. Most English teachers believe that it is the duty for instructors and counselors to conduct ideological and political education. So, the vast majority of English teachers only focus on the knowledge lecturing, whose teaching philosophy is confined to intellectual education.

\subsection{Lack of Teaching Procedures}

Through observation of teaching practice in class, we summarized that during the whole lecturing in class, teachers rarely mentioned ideological and political elements due to the limits of time as well as the teachers' inadequate preparation of moral education. These teachers hold that ideological and political education will largely take over the limited amount of class time. They 
automatically neglect the hidden education in the professional teaching. Consequently, students almost have no idea about the teachers' views and values not to mention ideological and political thoughts and gains through the English Courses.

\subsection{Lack of Teaching Material}

Generally speaking, the teaching material for English course are originally derived from the western culture in order to keep correspondence with the topic and objectives, regardless of the ideological and political elements. The editor and compiler mainly focus on the discourse and syntactic knowledge instead of ideological and political values let alone Chinese traditional virtues and culture. The trends in choosing of materials contribute little to developing the core socialist values and patriotism spirits.

\subsection{Defects in Evaluation Mechanism}

The effects and gains of ideological and political education are not so visible and immediate as other dimensions in teaching objectives in the short run which would be working and being aware of in the long span of life. Even though many teachers strain hardly to care students in moral education, they efforts harvest little in terms of acknowledgment and professional assessment. Teachers are caught frequently in such dilemma without top-level designing for measurement.

\subsection{Causes Analysis}

There are several causes leading to the paradox mention above. Firstly, the defects of ideological and political qualities hinder the teachers to conduct moral education naturally in routine teaching work. Lack of plastic and suitable stock of ideological and political material restricts teachers' freedom to teach and educate in terms of moral elements. Second, shortage of willingness and awareness in moral education restrains the unfolding of wide-ranging ideological and political education, which is due to the examination-oriented education ideas. Third, the obvious shortage of Chinese culture in English teaching materials restricts the teachers to a certain extent. Therefore, teachers hardly pitch ideological and political elements in the teaching materials. Finally, the teaching groups fail to cooperate functionally to conduct ideological and political education in collective lesson preparation. Collective discussion and communication concerning the moral education is seriously in need.

\section{THE PRINCIPLES AND COUNTERMEASURES}

\subsection{The Principles for Curriculum of Ideological and Political Education}

Firstly, the combination of English teaching and moral education should be conducted throughout the English class, which doesn't mean moral education dominates the whole class. During routine teaching activities, teachers should penetrate the Chinese culture, professional ethics, craftsman spirits and virtues into lecturing. Second, the combination of Chinese culture and Western culture. English teaching materials mainly introduce the advanced professional knowledge, service, technology and concepts in western world. So, teachers should encourage students to learn about China's corresponding parts and compare with that of western world. Only through such overall learning and study, can students build up a comprehensive knowledge system. Third, gradual advance in moral education. The ideological and political education should proceed in an orderly way step by step. The teaching scheme should be designed carefully and particularly suitable to the student's learning situation. Four, moderate and natural moral education. The English course are ideal carrier for ideological and political education in terms of its humanism qualities. Teachers can grasp any chance of educating during the lecturing to penetrate socialist core values into teaching, which is a hidden education in teacher's shoes, and an incidental learning in the students'.

\subsection{The Countermeasures}

The effective function of curriculum of ideological and political education cannot go without reforming and reconstruction in teaching material, methods and concepts hold by teachers. So, the corresponding countermeasures are derived from the four aspects.

\subsubsection{Teachers: the practitioners}

English teachers are critical practitioners in curriculum of ideological and political education in English course. Competent knowledge together with comprehensive qualities qualify their teaching and education and guarantee the teaching effects. The General Secretary Xi Jinping stressed in The National Conference on Ideological and Political Work in Colleges and Universities: "Teachers are engineers of human souls, they are backbones of cultivating talents, they are bearing the sacred mission to educate, to lead." [6]. So, the teachers should strengthen their awareness of ideological and political ideas at first. In addition, teachers should enhance the code of ethics and become the model for students teaching by precept and example. Finally, teachers should work lengths to improve teaching methods and update the designing for class in 
order to explore an effective and influential model of personnel cultivation.

\subsubsection{Teaching material: the source of learning}

The teaching contents make up the basis of teaching serving as the carrier for the whole teaching procedures. It is necessary to excavate the ideological and political elements through the teaching contents to promote the moral education together with political education. Teachers are supposed to reconstruct and reshape the original teaching materials to create for natural ideological and political education on the base of well mastery of the target contents. The teaching contents determine the results of teaching while the currently used materials are mainly from the western cultures which dominates the values systems thus, Chinese cultures and values seemingly invisible, which needs teachers to dig out the relative elements and expand fully to educate for moral goal. Such reconstruction of material is challenging and demanding for teachers, which requires teaches to devote more time and attention to the current affairs and politics from diverse perspective continuously.

\subsubsection{Teaching methods: the vehicle}

Besides creative reconstruction of the teaching contents, teachers should attach importance to designing of the classes and related teaching methods. Every teacher is supposed to update the teaching methods accordingly in improvement of class teaching designing. To be exact, teacher should transform the center of class to students integrating with task-based methods and experiential teaching method. Through flexible and diverse methods, the class atmosphere would be more active and the students would achieve more autonomy and independence.

\subsubsection{Extracurricular activities: the second classroom}

Extracurricular activities are practice for application of major theories. In the second classroom, students can actually experience and try their gains in traditional classes, which will cement the theories and ideological and political ideas in their minds.

\subsubsection{Internet and multimedia: the tools}

Our era is dominated with internet-plus models, in which one almost cannot go without internet. So, online learning, learning with multimedia, learning with technology are playing full roles in school time. Internet offers a platform without limits of time and place which functions actively and powerfully in every aspect of today's teaching and learning. Teaches should make full use of internet to conduct ideological and political education.

\subsection{The Related Administration Guarantees}

The effects and fruits of ideological and political education in colleges needs top-level design to guarantee the processing. Firstly, the guarantee for funds, which applied to teachers' training and further-studies in ideological and political education to ensure the first-line teachers' mastery of the correct and clear policies. Secondly, administrative management system should work for the procedures and conduction of ideological and political education. The syllabus and criterion for curriculum needs to be reformed according to moral targets. Finally, guarantee for sound school environment. The administration should pay attention to build a sound circumstance for students' growth physically and mentally. The ideological and political propaganda should be continuous and obvious in top-level designing.

\section{CONCLUSION}

On the basis of the analysis of the current problems of ideological and political education in the English course, together with the corresponding countermeasures, English teachers should adhere to the principles of combination of professional teaching with moral education naturally and intensively. Besides that, we should attach great importance to teachers' comprehensive qualities, teaching material reconstruction and teaching methods improvement and reforms. In order to implement these reforming and principles more effectively, the top-level design is vitally needed. This thesis can serve as effective theory guidance in curriculum moral education and a complement for specialized ideological and political courses.

\section{REFERENCES}

[1] "Play the strongest voice of all-round education" people's network, February,2019.

[2] Hushi, "Dewey's Moral Education". [M] Anhui Education Press. 1995.

[3] Sukhomlonsky "How to Cultivate true human?" [M] Beijing Education and Science Press. 1992

[4] Jim Rogers, "The Freedom to Learning". Beijing Normal University Press, Beijing, 2006

[5] Brown, H.D. "Teaching by principles: An interactive approach to language pedagogy." Foreign Language Teaching and Research Press, 2004.

[6] Xi Jinping. "Speech in Beijing Normal University" http:// www. China-news.com/gn/2014/09/10/ 6575002.s html. 